Check for updates

Cite this: RSC Adv., 2019, 9, 18245

\title{
Rational design of a polypyrrole-based competent bifunctional magnetic nanocatalyst $\uparrow$
}

\begin{abstract}
Wael A. Amer, (D) ${ }^{a}$ Basel Al-saida (D) ab and Mohamad M. Ayad (D) *ac
The combination of conducting polymers with semiconductors for the fabrication of organic/inorganic hybrid nanocatalysts is one of the most promising research areas for many applications. In this work, the synthesized nanocomposite combines several advantages such as the photoresponse shift from the UV region toward visible light by narrowing the band gap of the semiconductor, magnetic separation ability and dual applications including the catalytic reduction of $p$-nitrophenol (PNP) and the photocatalytic degradation of methylene blue (MB) dye. In addition to the core magnetite nanoparticles (NPs), the synthesized nanocomposite contains polypyrrole (PPY) and $\mathrm{TiO}_{2}$ shells that are decorated with silver metal NPs to prevent electron-hole recombination and to enhance the catalytic performance. Indeed, the catalytic PNP reduction experiments reveal that the synthesized nanocomposite exhibits significantly high catalytic activity with a rate constant of $0.1169 \mathrm{~min}^{-1}$. Moreover, the photocatalytic experiments show that the synthesized nanophotocatalyst has a boosting effect toward MB dye degradation under normal daytime visible light irradiation with a rate constant of $6.38 \times 10^{-2} \mathrm{~min}^{-1}$. The synergetic effect between silver NPs, PPY and $\mathrm{TiO}_{2}$ is thought to play a fundamental role in enhancing the photocatalytic activity.
\end{abstract}

Received 4th April 2019

DOI: $10.1039 / c 9 r a 02544 h$

rsc.li/rsc-advances

\section{Introduction}

Nowadays, catalysis is described as a central field of nanoscience beside its essential role in "Green Chemistry". Catalysis is divided into two divisions, homogeneous and heterogeneous. Homogeneous catalysts have several advantages such as high selectivity and good yield, but the difficulty of catalyst separation and recovery from the final product are critical challenges and thus heterogeneous catalysts are considered to be more practical for their stability at high temperatures, inexpensive recycling, and their easy removal from the reaction medium. ${ }^{1} \mathrm{~A}$ wide range of heterogeneous nanocatalysts were used in environmental applications specifically to reduce/degrade organic compounds. ${ }^{2,3}$ For example, Au-Pd nanocatalyst was prepared and used for the catalytic reduction of $o$-nitrophenol. Naked $\mathrm{Ni}$ nanocatalyst was synthesized for $p$-nitrophenol (PNP) reduction, but the problem with this nanocatalyst lies in its aggregation and partial sintering that could result in its deactivation. ${ }^{4}$

Due to such kind of problems, composites of nanomaterials with conducting polymers attracted much attention in the

${ }^{a}$ Chemistry Department, Faculty of Science, Tanta University, Tanta 31527, Egypt ${ }^{b}$ Chemistry Department, Faculty of Science, Al-Balqa Applied University, Al-Salt 19117, Jordan

'Institute of Basic and Applied Sciences, Egypt-Japan University of Science and Technology, New Borg El-Arab City, Alexandria 21934, Egypt. E-mail: mohamad. ayad@ejust.edu.eg; Fax: +20 3459 9520; Tel: +20 34599520

$\dagger$ Electronic supplementary information (ESI) available. See DOI: $10.1039 / \mathrm{c} 9 \mathrm{ra02544h}$ recent decades, and the study of this kind of nanocomposites has becoming one of the most active and promising research areas. Polypyrrole (PPY)-based nanocomposites have a great deal of attention, due to their easy synthesis, high electrical conductivity, high absorption coefficient in the visible light, charge carriers with high mobility, and the good environmental stability. ${ }^{5}$ On other hand, PPY is infusible, insoluble and exhibits pauper processability. To overcome these problems, PPY composites with metal nanoparticles (NPs) were synthesized with significant strategies. For example, PPY@Ag composite was synthesized via the direct redox reaction between $\mathrm{AgNO}_{3}$ and pyrrole for the reduction of PNP by $\mathrm{NaBH}_{4}$, but 44 minutes were required for the reduction process, and the kinetic reaction rate constant was estimated to be very small $\left(0.011 \mathrm{~min}^{-1}\right){ }^{6}$ PPY-coated cotton fabric decorated with silver NPs was synthesized for the catalytic reduction of PNP in which 32 minutes were necessary to complete the reduction process using $1 \mathrm{mg}$ of catalyst and a relatively small kinetic rate constant $\left(0.0371 \mathrm{~min}^{-1}\right)$ was obtained. ${ }^{7}$ Nowadays, the polymer-based three-component research became an important issue, such as $\alpha-\mathrm{Fe}_{2} \mathrm{O}_{3} / \mathrm{PPY} / \mathrm{Ag}$ which was synthesized for the reduction of sodium $m$-nitrobenzene sulfonate with which $4 \mathrm{mg}$ of the nanocatalyst required a relatively long time to complete the reduction process. ${ }^{8}$

In addition, PPY composites with different inorganic materials such as $\mathrm{TiO}_{2}, \mathrm{ZnO}, \mathrm{CdS}, \mathrm{SnO}_{2}, \mathrm{CuO}$ and $\mathrm{CeO}^{9-12}$ were widely synthesized. Among these materials, titanium dioxide is an excellent photocatalyst due to its effectiveness, photostability, 
availability, reusability and non-toxicity. ${ }^{13} \mathrm{TiO}_{2}$ shows high photocatalytic activity due to its low band gap $\approx 3.2 \mathrm{eV} \cdot{ }^{\mathbf{1 4}}$ Furthermore, the coating of $\mathrm{TiO}_{2}$ with PPY could attenuate the agglomeration and show firmer absorbance than bare $\mathrm{TiO}_{2} \cdot{ }^{15}$ PPY-modified $\mathrm{TiO}_{2}$ nanocomposites respond easily toward the visible light as PPY narrows the band gap of $\mathrm{TiO}_{2}$ and thus the band gap energy value for $\mathrm{PPY}-\mathrm{TiO}_{2}$ nanocomposites becomes smaller than that of $\mathrm{TiO}_{2} \cdot{ }^{16}$ Wang et al. improved $\mathrm{TiO}_{2}$ properties with PPY via the in situ polymerization of pyrrole hydrochloride employing ferric chloride as an oxidizing agent in the presence of $\mathrm{TiO}_{2}$. The $\mathrm{TiO}_{2}$ aggregations were reduced by PPY modifications, but $450 \mathrm{mg}$ of this nanocatalyst were used for methyl orange degradation under the sun light with a low degradation rate constant $\left(0.0086 \mathrm{~min}^{-1}\right) .{ }^{17}$

The updated research trends involve the incorporation of additional components, such as noble and/or transition metals, in the $\mathrm{TiO}_{2} / \mathrm{PPY}$ structures. The doping $\mathrm{TiO}_{2} / \mathrm{PPY}$ structures with silver, palladium and gold attracted much attention due to their high conductivity, excellent catalytic behavior, and the surface plasmon resonance in visible light region in addition to the synergistic effect for narrowing of $\mathrm{TiO}_{2}$ band gap and enhancing the photocatalytic activity. ${ }^{18}$ Moreover, the interaction between metal NPs and PPY chains is expected to prevent or reduce the leaching of the metal NPs into the solution. ${ }^{19} \mathrm{PPY} /$ $\mathrm{TiO}_{2}$ nanocomposites were used as nanoreactors for loading Pd nanocatalysts towards PNP reduction. ${ }^{20}$ Silver NPs were extensively used with different substrates due to their significantly optical properties, unique electrical and antibacterial properties. ${ }^{21}$ Kuo et al. prepared $\mathrm{Ag} / \mathrm{TiO}_{2}$ films on glass substrates by radiofrequency sputtering and a good performance was obtained for dye degradation but the problem lies in the complicated synthetic procedures. $^{22}$

Out of our knowledge, few research deals with four components-based nanocatalysts. Additionally, most of the current research focuses on the design of nanocatalysts with multifunctional behavior. In the present study, we described procedures for the synthesis of a low cost and efficient magnetic nanocatalyst composed of four-components of Ag-PPY/TiO ${ }_{2} @-$ $\mathrm{Fe}_{3} \mathrm{O}_{4}$ (MTPS). The synthesized magnetic nanocomposite acts as a highly efficient magnetic nanocatalyst with a synergetic effect between all its components: PPY, $\mathrm{TiO}_{2}$, magnetite $\left(\mathrm{Fe}_{3} \mathrm{O}_{4}\right)$ and $\mathrm{Ag}$ NPs. Magnetite seeds act as a core to facilitate the separation process of the catalyst from the solution by applying an external magnetic field. ${ }^{23}$ The magnetite incorporation in other matrices can prevent the air oxidation and the agglomeration of magnetite particles. ${ }^{24}$ Due to their excellent surface energy and magnetic properties, $\mathrm{Fe}_{3} \mathrm{O}_{4}$ NPs are thermodynamically unstable and prone to agglomeration. Hence, the modification or the formation of a coating on the magnetic NPs could serve as a protective layer against oxidation and some extreme chemical environments. ${ }^{25}$ In our work, the silane agents APTES was used for the direct surface modification of $\mathrm{Fe}_{3} \mathrm{O}_{4}$ NPs to obtain high density surface of $-\mathrm{NH}_{2}$ functional groups that facilitate the next step of $\mathrm{TiO}_{2}$ functionalization, which was performed in alkaline conditions using titanium $n$-butoxide (ТВОT) as a precursor. Afterward, $\mathrm{Fe}_{3} \mathrm{O}_{4} @ \mathrm{TiO}_{2} / \mathrm{PPY}$ nanocomposite was decorated with Ag NPs, which are relatively the most suitable noble metal for industrial applications due to its easy preparation and low cost. Subsequently, the MTPS nanocomposite was fully characterized by X-ray diffraction (XRD), Fourier transform infrared (FTIR) spectroscopy, scanning electron microscopy (SEM), energy dispersive X-ray (EDX), and transmission electron microscopy (TEM). The catalytic efficiency of MTPS nanocomposite was evaluated toward the reduction of PNP as a model of the most hazardous and toxic nitroaromatic compounds. Furthermore, the photocatalytic activity of the synthesized MTPS nanocomposite toward the degradation of methylene blue (MB) dye was studied as well. All reactions were carried out under the day visible light and at room temperature.

\section{Experimental}

\subsection{Chemicals}

Pyrrole (Aldrich) was kept below $5{ }^{\circ} \mathrm{C}$ in the absence of light. Anhydrous $\mathrm{FeCl}_{3}$ 98\% (Aldrich), 3-triethoxysilylpropylamine (APTES, 99\%, Aldrich), $\mathrm{FeCl}_{2} \cdot 4 \mathrm{H}_{2} \mathrm{O}$ (Aldrich), titanium $n$-butoxide (Sigma Aldrich, TBOT), $\mathrm{NaOH}$ pellets (LobaChemie, India) were used as received. $\mathrm{NH}_{4} \mathrm{OH}$ solution ( $25 \mathrm{wt} \%$ ), silver nitrate (BDH, UK), sodium boron hydride $\left(\mathrm{NaBH}_{4}\right)$ (Johnson Matthey, UK), 4-nitrophenol (PNP) (Sigma Aldrich), and methylene blue (MB) were used without further purification.

\subsection{Synthesis of magnetite $\left(\mathrm{Fe}_{3} \mathrm{O}_{4}\right)$}

Firstly, $\mathrm{FeCl}_{3} \cdot 6 \mathrm{H}_{2} \mathrm{O}(4 \mathrm{~mL}, 2 \mathrm{M})$ and $\mathrm{FeCl}_{2} \cdot 4 \mathrm{H}_{2} \mathrm{O}(2 \mathrm{~mL}, 2 \mathrm{M})$ were mixed and stirred for $45 \mathrm{~min}$ at $30{ }^{\circ} \mathrm{C}$. The molar ratio of $\mathrm{Fe}(\mathrm{III}) / \mathrm{Fe}(\mathrm{II})$ was kept 2 . Under $\mathrm{N}_{2}$ gas atmosphere, ammonia solution $(100 \mathrm{~mL}, 1 \mathrm{M})$ was added dropwise to the previous solution and $\mathrm{pH}$ of the mixture was adjusted to 10 . The solution was stirred for about $1 \mathrm{~h}$ until black $\mathrm{Fe}_{3} \mathrm{O}_{4}$ particles appeared. The product was filtrated and rinsed with distilled water and methanol until neutral filtrate was obtained. The produced $\mathrm{Fe}_{3} \mathrm{O}_{4}$ NPs were eventually dried at $60{ }^{\circ} \mathrm{C}$ for $24 \mathrm{~h}^{26}$ The following reaction describes the formation of $\mathrm{Fe}_{3} \mathrm{O}_{4} \mathrm{NPs}^{27}$

$$
\mathrm{Fe}_{(\mathrm{aq})}{ }^{+2}+2 \mathrm{Fe}_{(\mathrm{aq})}{ }^{+3}+8 \mathrm{OH}_{(\mathrm{aq})}{ }^{-} \rightarrow \mathrm{Fe}_{3} \mathrm{O}_{4(\mathrm{~S})}+4 \mathrm{H}_{2} \mathrm{O}_{(\mathrm{l})}
$$

\subsection{Preparation of functionalized magnetite $\left(\mathrm{Fe}_{3} \mathrm{O}_{4}-\mathrm{NH}_{2}\right)$ NPs}

To a magnetite ethanolic suspension $\left(5 \mathrm{mg} \mathrm{mL}^{-1}\right)$, (3-aminopropyl)triethoxysilane (APTES) $(0.8 \mathrm{~mL})$ was added and the mixture was stirred under $\mathrm{N}_{2}$ atmosphere for 4 h. $\mathrm{Fe}_{3} \mathrm{O}_{4}-\mathrm{NH}_{2}$ NPs were collected magnetically and rinsed with ethanol and deionized water three times. ${ }^{25}$

\subsection{Synthesis of $\mathrm{Fe}_{3} \mathrm{O}_{4} @ \mathrm{TiO}_{2}$ nanospheres}

$\mathrm{Fe}_{3} \mathrm{O}_{4}-\mathrm{NH}_{2}$ NPs were dispersed in a mixed solvent of $250 \mathrm{~mL}$ ethanol and $90 \mathrm{~mL}$ acetonitrile. The dispersion was sonicated for $15 \mathrm{~min}$ and $1.5 \mathrm{~mL}$ of $\mathrm{NH}_{4} \mathrm{OH}$ solution (25 wt\%) was added. Next, the reaction mixture was kept under mechanical stirring for $30 \mathrm{~min}$ and $3 \mathrm{~mL}$ of TBOT (previously dissolved in $20 \mathrm{~mL}$ of ethanol) was added under mechanical stirring at $30^{\circ} \mathrm{C}$ for $1.5 \mathrm{~h}$ 
to get $\mathrm{Fe}_{3} \mathrm{O}_{4} @ \mathrm{TiO}_{2}$ core/shell nanospheres. The product was magnetically collected, separated and washed with absolute ethanol three times. ${ }^{28}$

\subsection{Synthesis of $\mathrm{Fe}_{3} \mathrm{O}_{4} @ \mathrm{TiO}_{2} / \mathrm{PPY}$ nanocomposite}

$0.03 \mathrm{~g}$ of $\mathrm{Fe}_{3} \mathrm{O}_{4} @ \mathrm{TiO}_{2}$ was dispersed in $200 \mathrm{~mL}$ of $1 \mathrm{M} \mathrm{HCl}$ and sonicated for $30 \mathrm{~min}$. Pyrrole $(0.756 \mathrm{~mL})$ was added dropwise with vigorous stirring to the previous suspension for $30 \mathrm{~min}$. Subsequently, $\mathrm{FeCl}_{3}$ (4.33 $\mathrm{g}$ in $27 \mathrm{~mL}$ deionized water) was quickly added to polymerize the adsorbed pyrrole on $\mathrm{Fe}_{3} \mathrm{O}_{4}$ @$\mathrm{TiO}_{2}$. The reaction was kept for $24 \mathrm{~h}$ at $5{ }^{\circ} \mathrm{C}$ and the product was collected with a magnet and rinsed with water and ethanol three times then the composite was dried for $15 \mathrm{~h}$ at $60{ }^{\circ} \mathrm{C} .{ }^{29}$

\subsection{Synthesis of MTPS nanocomposite}

$0.2 \mathrm{~g}$ of $\mathrm{Fe}_{3} \mathrm{O}_{4} @ \mathrm{TiO}_{2} / \mathrm{PPY}$ nanocomposite was dispersed in $200 \mathrm{~mL} \mathrm{NH}_{4} \mathrm{OH}(0.1 \mathrm{M})$ and stirred for $4 \mathrm{~h}$. After filtration, the nanocomposite was added in another $200 \mathrm{~mL}^{\circ} \mathrm{NH}_{4} \mathrm{OH}(0.1 \mathrm{M})$ for $4 \mathrm{~h}$ and filtered. The product was collected, rinsed with ethanol and distilled water three times, and dried at $60{ }^{\circ} \mathrm{C}$ for $24 \mathrm{~h}$. The final product was dispersed in $\mathrm{AgNO}_{3}$ solution $(0.005$ $\mathrm{M})$ and stirred for $8 \mathrm{~h}$ and then the resulting nanocomposite was collected magnetically. ${ }^{30}$ Scheme 1 shows the synthesis procedures of MTPS nanocomposite.

\subsection{Catalytic activity of MTPS nanocomposite}

To evaluate the catalytic efficiency of MTPS nanocomposite, the reduction of PNP to $p$-aminophenol (PAP) using $\mathrm{NaBH}_{4}$ as a reductant was selected as a model reaction. The catalytic reduction reaction was executed in a standard quartz cuvette, $2.5 \mathrm{~mL}$ of $7 \times 10^{-5} \mathrm{M}$ of alkaline PNP solution was mixed with $1 \mathrm{mg}$ of the nanocatalyst, and the absorption spectra were recorded. Afterward, $0.5 \mathrm{~mL}$ of freshly prepared $\mathrm{NaBH}_{4}$ solution (10 $\mathrm{mg} \mathrm{mL}^{-1}$ ) was added to the previous solution, then the reduction progress was monitored via the measurement of the absorption spectra over time. ${ }^{31}$

\subsection{Photocatalytic activity of MTPS nanocomposite}

The photocatalytic activity of MTPS nanocomposite was evaluated by studying the degradation of MB dye solution as a model reaction under the normal day visible light at room temperature. $40 \mathrm{mg}$ of the nanocatalyst was dispersed into $100 \mathrm{~mL}$ aqueous $\mathrm{MB}$ solution $\left(4 \mathrm{mg} \mathrm{L}^{-1}\right)$. Before visible light irradiation, the suspension of MB dye and the nanocatalyst was stirred for $15 \mathrm{~min}$ in the dark for establishing equilibrium between adsorption and desorption of MB dye on the nanocatalyst's surface. The absorption peak of MB at $664 \mathrm{~nm}$ was used for following the photocatalytic degradation process. ${ }^{32}$

\subsection{Characterization}

X-ray powder diffraction patterns (XRD) of the products were obtained on a Japan Rigaku D Max- $\gamma$ A rotation anode X-ray diffractometer equipped with graphite monochromatized $\mathrm{Cu}$ $\mathrm{K} \alpha$ radiation $(\lambda=1.54178 \AA$ ). The bulk (as well as the elemental mapping) and the surface morphology of the MTPS nanocomposite were examined using a transmission electron microscope (TEM) (JEM-2100F) at $200 \mathrm{kV}$ and a scanning electron microscope (SEM) (Hitachi S4800) with $5 \mathrm{kV}$ accelerating voltage, respectively. The magnetic properties were investigated using a vibrating sample magnetometer (VSM). A Bruker, Tensor 27 FT-IR spectrophotometer was used to measure the Fourier transform infrared spectra (FT-IR) in a frequency range of $4000-400 \mathrm{~cm}^{-1}$. A UV spectrometer, UVD-2960 (Labomed Inc.) was exploited for recording the UV-vis absorption spectra. The UV-vis diffuse reflectance spectra (DRS) were recorded using Shimadzu UV-2450 spectrophotometer.

\section{Results and discussion}

X-ray diffraction (XRD) enables the identification of the phase and crystallinity of the synthesized MTPS nanocomposite. Fig. $1 \mathrm{~A}$ represents the diffraction patterns of $\mathrm{Fe}_{3} \mathrm{O}_{4}$ at $2 \theta$ equivalent to $30.2^{\circ}, 35.74^{\circ}, 43.12^{\circ}, 53.51^{\circ}, 57.19^{\circ}$ and $62.78^{\circ}$ that can be indexed to $(h k l)$ reflection peaks of [220], [311], [400], [422], [511] and [440], respectively for face centered cubic (FCC) phase of magnetite. ${ }^{33}$ After the coating with a $\mathrm{TiO}_{2}$ layer, characteristic diffraction peaks appeared at $25.3^{\circ}$ and $37.9^{\circ}$ that matched the standard anatase $\mathrm{TiO}_{2}$ crystal planes of [101] and [004], respectively (JCPDS 21-1272). The other diffraction peaks that are characteristic to the crystal planes of the standard anatase $\mathrm{TiO}_{2}$ were fused with the peaks of magnetite. In Fig. 1C, a broad peak around $25^{\circ}$ is associated with the presence of amorphous PPY $^{34}$ indicating that amorphous PPY exists on the surface of $\mathrm{TiO}_{2},{ }^{35}$ while the peaks ascribed to the [111], [200], [220] and [311] planes of FCC of Ag phase appeared at $2 \theta$ of $38^{\circ}$, $44^{\circ}, 65^{\circ}$ and $77^{\circ}$ (JCPDS card no. 040783). ${ }^{36}$ The peak of $\mathrm{Fe}_{3} \mathrm{O}_{4}$ located at $2 \theta \sim 35.7^{\circ}$ was found to be merged with the [111]

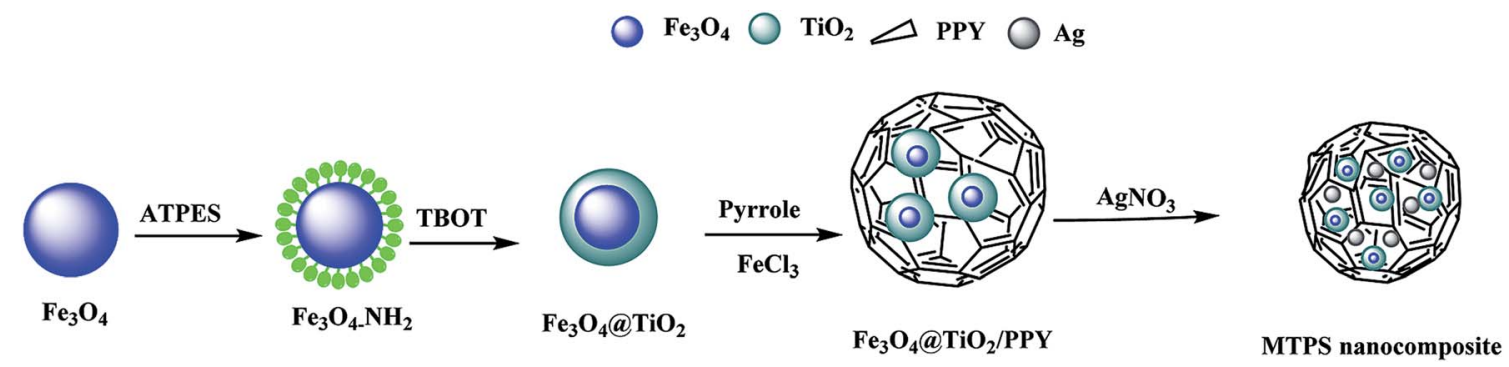

Scheme 1 The formation mechanism of MTPS nanocomposite. 


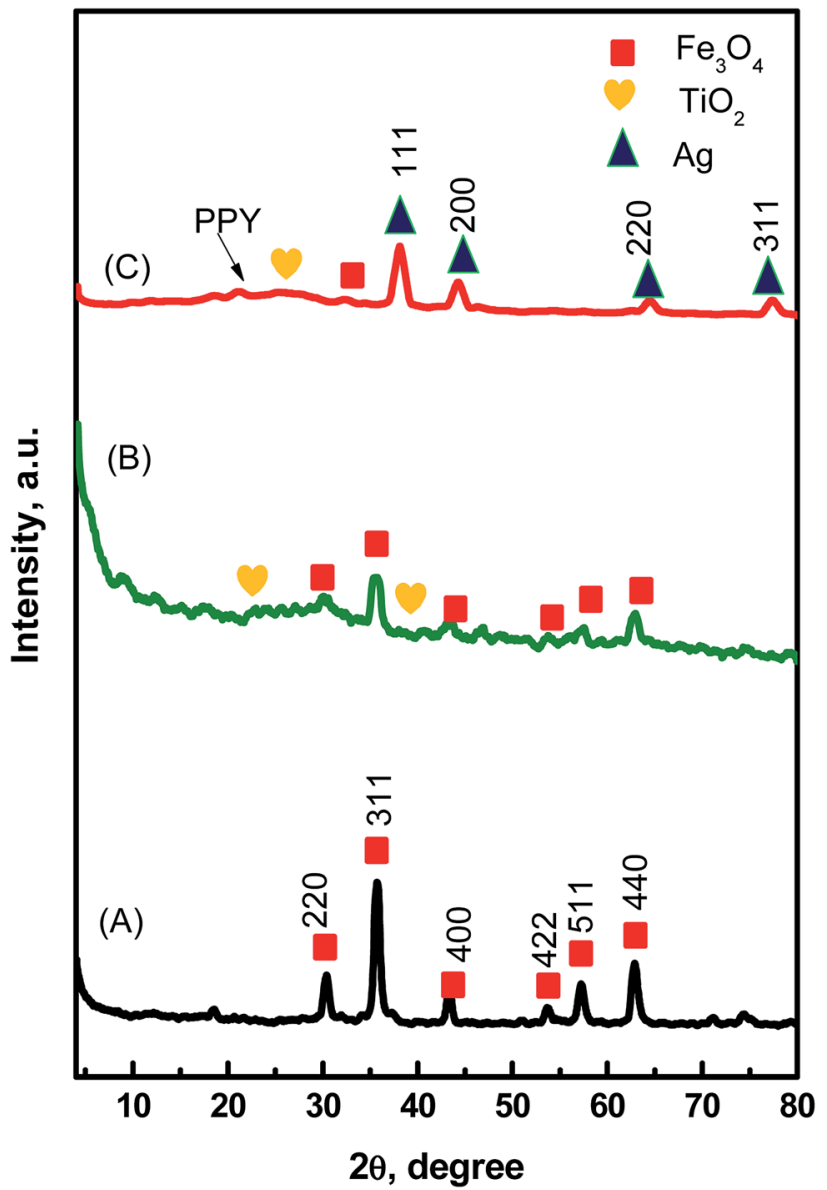

Fig. 1 XRD patterns of the prepared $\mathrm{Fe}_{3} \mathrm{O}_{4} \mathrm{NPs}(\mathrm{A}), \mathrm{Fe}_{3} \mathrm{O}_{4}\left(\mathrm{aTiO} \mathrm{T}_{2}\right.$ nanospheres (B), and MTPS nanocomposite (C).

anatase phase of $\mathrm{Ag}$ during the formation of MTPS nanocomposite. Moreover, the presence of a new peak at $2 \theta \sim 77^{\circ}$ corresponds to (311) anatase phase of $\mathrm{Ag}$, which confirms the presence of Ag NPs and hence the formation of MTPS nanocomposite is confirmed.

The structural information and chemical components of MTPS nanocomposite were identified by the FTIR spectra (Fig. 2). As shown in (Fig. 2A), the characteristic peak of $\mathrm{Fe}_{3} \mathrm{O}_{4}$ at $589 \mathrm{~cm}^{-1}$ arose from the stretching vibration of Fe-O bond. ${ }^{37}$ The peaks at 3409 and $1618 \mathrm{~cm}^{-1}$ are attributed to the $-\mathrm{NH}_{2}$ group bending and primary amine vibration..$^{38}$ In Fig. 2B, the peak at $1364 \mathrm{~cm}^{-1}$ is attributed to the stretching vibration of Ti$\mathrm{O}$, while the broad band in the range $500-700 \mathrm{~cm}^{-1}$ resulted

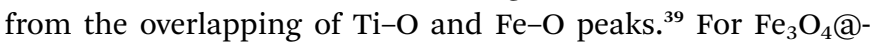
$\mathrm{TiO}_{2} / \mathrm{PPY}$ nanocomposite (Fig. 2C), the peak at $3429 \mathrm{~cm}^{-1}$ is due to the vibration of $\mathrm{N}-\mathrm{H}$, and the peaks at 1349 and $1614 \mathrm{~cm}^{-1}$ are induced by $\mathrm{C}-\mathrm{N}$ and $\mathrm{C}=\mathrm{C}$ on the pyrrole ring, respectively. ${ }^{40}$ In Fig. 2C, it was observed that the intensity of the peak at $400-$ $700 \mathrm{~cm}^{-1}$ is lower than that in the spectrum of $\mathrm{Fe}_{3} \mathrm{O}_{4} @ \mathrm{TiO}_{2}$, which may be ascribed to the wrapping of $\mathrm{TiO}_{2}$ with PPY. ${ }^{29}$ Upon anchoring $\mathrm{Ag}$ NPs, the peak at $1614 \mathrm{~cm}^{-1}$ of $\mathrm{C}=\mathrm{C}$ shown little shift, with decreasing intensity, to $1545 \mathrm{~cm}^{-1}$ due to silver coordination with the nitrogen atoms of PPY (Fig. 2D)..$^{41,42}$

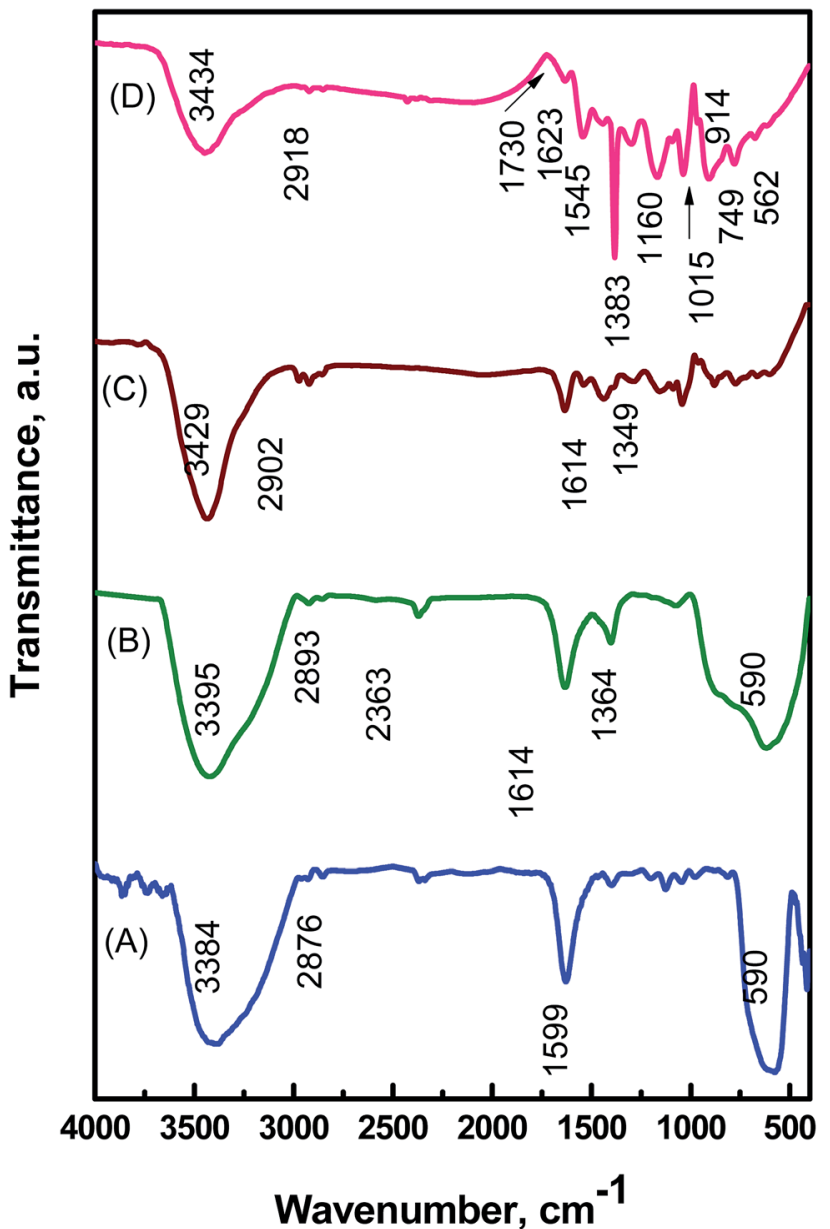

Fig. 2 FTIR spectra of the $\mathrm{Fe}_{3} \mathrm{O}_{4} \mathrm{NPS}(\mathrm{A})$, and $\mathrm{Fe}_{3} \mathrm{O}_{4} \mathrm{aTiO}_{2}$ nanospheres (B), $\mathrm{Fe}_{3} \mathrm{O}_{4} \mathrm{OTiO}_{2} / \mathrm{PPY}$ nanocomposite (C), and MTPS nanocomposite (D).

Furthermore, a strong peak at $1383 \mathrm{~cm}^{-1}$ was clearly observed due to the counter nitrate anion $\left(\mathrm{NO}_{3}{ }^{-}\right)$stretching, ${ }^{43}$ and the interactions between Ag NPs and PPY interface. ${ }^{44}$ This peak was much stronger than in $\mathrm{Fe}_{3} \mathrm{O}_{4} @ \mathrm{TiO}_{2} / \mathrm{PPY}$ nanocomposite, which can be attributed to the amplified contribution of the chargetransfer effect between the PPY chains and silver NPs. ${ }^{45}$

The bulk morphology of the synthesized nanocomposites was examined by measuring their TEM images. Spherical $\mathrm{Fe}_{3} \mathrm{O}_{4}$ NPs in a diameter of $\sim 10 \mathrm{~nm}$ were observed in Fig. 3A with uniform distribution without any serious aggregation. After coating with $\mathrm{TiO}_{2}$ (Fig. 3B), a layer of $\mathrm{TiO}_{2}$ ( $\sim 30 \mathrm{~nm}$ thickness) was formed, and the $\mathrm{TiO}_{2}$ layer was dispersed uniformly. In addition, the dense array of $\mathrm{Fe}_{3} \mathrm{O}_{4} @ \mathrm{TiO}_{2} / \mathrm{PPY}$ is shown in Fig. 3C. The size of $\mathrm{Fe}_{3} \mathrm{O}_{4} @ \mathrm{TiO}_{2} / \mathrm{PPY}$ nanocomposite appears to be greater than that of the $\mathrm{Fe}_{3} \mathrm{O}_{4} @ \mathrm{TiO}_{2}$ nanospheres that is an evidence for the successful deposition of PPY onto $\mathrm{Fe}_{3} \mathrm{O}_{4} @ \mathrm{TiO}_{2}$ nanospheres as a matrix. For $\mathrm{Fe}_{3} \mathrm{O}_{4} @ \mathrm{TiO}_{2} / \mathrm{PPY}$ nanocomposite, the $\mathrm{TiO}_{2} / \mathrm{PPY}$ shells are about $60 \mathrm{~nm}$ in thickness and the average size of $\mathrm{Fe}_{3} \mathrm{O}_{4} @ \mathrm{TiO}_{2} / \mathrm{PPY}$ nanostructures is about $80 \mathrm{~nm}$. Hence, the presence of PPY in the composite is able to reduce the $\mathrm{TiO}_{2} \mathrm{NPs}$ agglomeration. However, the TEM image of MTPS 


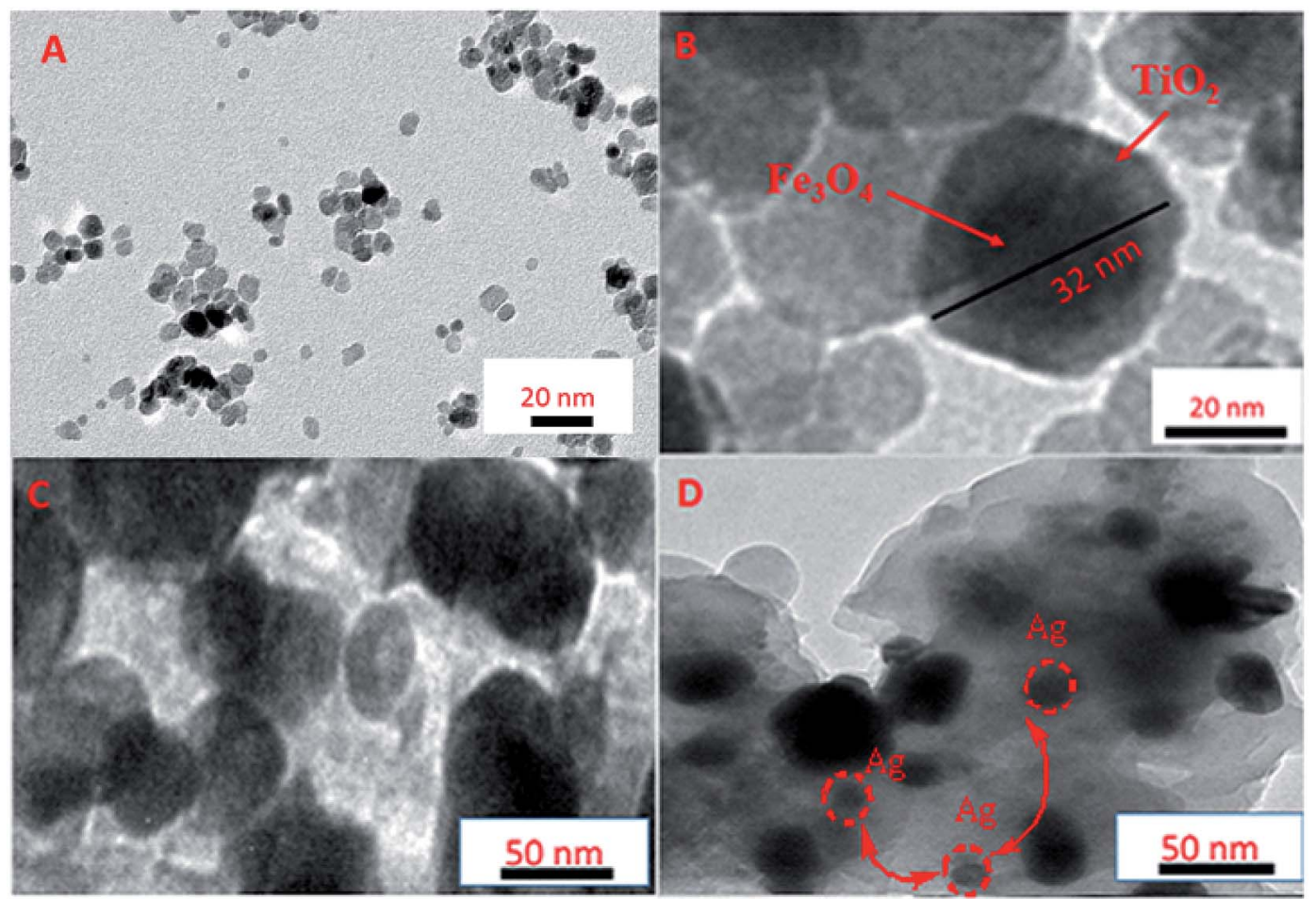

Fig. 3 TEM images of (A) $\mathrm{Fe}_{3} \mathrm{O}_{4}$ NPs, (B) $\mathrm{Fe}_{3} \mathrm{O}_{4}\left(\mathrm{aTiO}_{2}\right.$ nanospheres, (C) $\mathrm{Fe}_{3} \mathrm{O}_{4}\left(\mathrm{CTiO}_{2} / \mathrm{PPY}\right.$ nanocomposite, and (D) MTPS nanocomposite.

nanocomposite is presented in Fig. 3D that shows uniform distribution of Ag NPs without serious aggregations, and some black dots clearly observed that Ag NPs deposited on the polymer matrix. This confirms the successful synthesis of MTPS hybrid material.

The SEM image of MTPS nanocomposite is presented in Fig. 4A and it exhibits nanospheres with a mean diameter of $300 \mathrm{~nm}$ as a stacked structure, and the denser array of MTPS nanocomposite can be observed clearly. To identify the chemical composition, the EDX spectra of MTPS nanocomposite was measured (Fig. 4 B) that showed the existence of titanium, oxygen, iron, carbon, silver and nitrogen. A low percentage of iron is observed in the surface of MTPS nanocomposite, which indicates that the largest percentage of iron is found in the core. The inclusion of all elements in MTPS nanocomposite was further investigated by measuring the elemental mapping (Fig. S1, ESI†). The results confirm the existence of $\mathrm{C}, \mathrm{O}, \mathrm{N}, \mathrm{Fe}, \mathrm{Ti}$ and $\mathrm{Ag}$ with a good distribution through the synthesized MTPS nanocomposite.

The interior of magnetic $\mathrm{Fe}_{3} \mathrm{O}_{4}$ particles could satisfy the easy separation and achieve the regeneration of the catalyst after being used. ${ }^{46}$ The VSM was carried out and the magnetization curves of the synthesized nanocomposites are shown in Fig. 5. The saturation magnetization of magnetite decreased obviously after coating with $\mathrm{TiO}_{2}$ and PPY. However, the magnetism of catalyst is still enough to be used for the magnetic separation by an external magnetic field. Saturation mass magnetization (Ms) of the $\mathrm{Fe}_{3} \mathrm{O}_{4} @ \mathrm{TiO}_{2}$ and MTPS nanocomposite observed from Fig. 5 are 6.9 and 3.85 emu $\mathrm{g}^{-1}$, respectively. The magnetization of MTPS nanocomposite is enough for the easy recovery from the solution.

The optical properties of $\mathrm{Fe}_{3} \mathrm{O}_{4}, \mathrm{Fe}_{3} \mathrm{O}_{4} @ \mathrm{TiO}_{2}$ and MTPS nanocomposite were investigated by the UV-vis diffuse

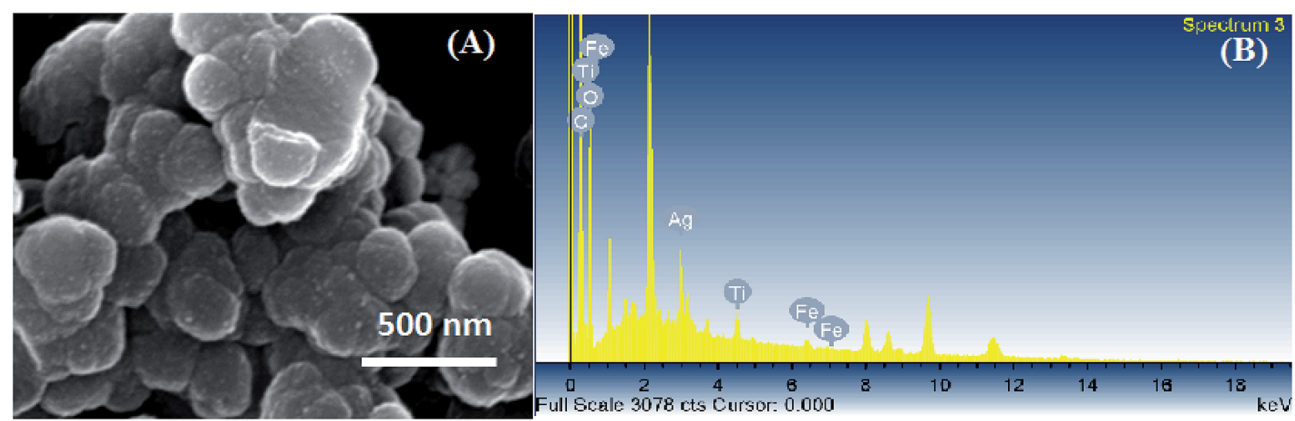

Fig. 4 (A) SEM and (B) EDX of MTPS nanocomposite. 


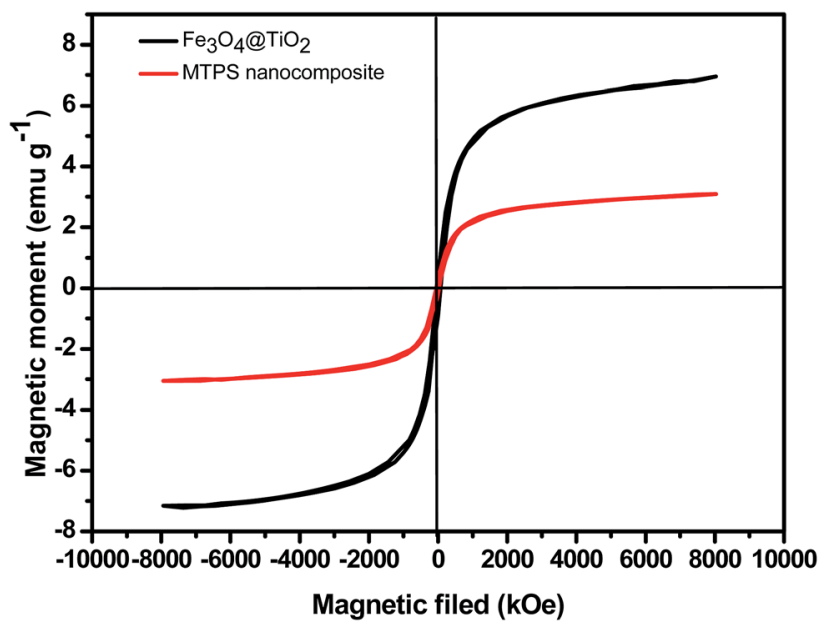

Fig. 5 Magnetic hysteresis loop $(\mathrm{M}-\mathrm{H})$ of $\mathrm{Fe}_{3} \mathrm{O}_{4} \mathrm{QTiO}_{2}$ and MTPS nanocomposite.

reflectance spectroscopy in the wavelength range of 200$800 \mathrm{~nm}$. As revealed from Fig. S2(A), $†$ MTPS nanocomposite displays higher light absorption in the visible spectrum region. This high absorption can be assigned to the photosensitization of PPY for trapping a huge number of visible light photons and to the surface plasmon resonance of electrons present in the Ag NPs induced by visible light. ${ }^{18}$ This result indicates that incorporation of $\mathrm{TiO}_{2}, \mathrm{PPY}$ and $\mathrm{Ag}$ with magnetite can extend the $\mathrm{TiO}_{2}$ spectral response range to the visible light region. This provides the ability for applying MTPS nanocomposite to the solar energy catalytic photodegradation of organic pollutants with a high photocatalytic activity. Fig. S2(A) $\dagger$ shows the UV-vis DRS of the assynthesized nanomaterials which was then used to calculate the band gaps via using the following Kubelka-Munk equation.

$$
F(R)=K / S
$$

where, $F(R)$ is the Kubelka-Munk function and $K$ is the molar absorption coefficient that equal $(1-R)^{2}, S$ is the scattering factor that equals $2 R$ ( $R$ is the reflectance) ${ }^{47}$ After plotting $[F(R)$ $E]^{1 / 2} v s . E(\mathrm{eV})$ and by extrapolating the linear portion obtained in the regression (as shown in Fig. S2(B) $\dagger$ ), the band-gap energies of the nanomaterials were found to be 1.66, 3.37 and $1.53 \mathrm{eV}$ for magnetite, $\mathrm{Fe}_{3} \mathrm{O}_{4} @ \mathrm{TiO}_{2}$ and MTPS nanocomposite, respectively. This indicates that MTPS nanocomposite possesses a smaller band gap than the other synthesized nanomaterials, suggesting the presence of synergistic effect among all the components in the quaternary MTPS nanocomposite. The reduction of the band gap allows the composite to capture easily and to utilize the visible light that can play a vital role in enhancing the photocatalytic activity.

PNP reduction reaction to PAP is a model reaction for testing the catalytic activity of MTPS nanocomposite using $\mathrm{NaBH}_{4}$ as a reducing agent and a hydrogen source for the reduction reaction.
No change in the PNP color was observed in its uncatalyzed reduction reaction. A catalyst, such as MTPS nanocomposite, is required for enhancing the electrons' transfer from the electron donor $\left(\mathrm{BH}_{4}{ }^{-}\right)$to the electron acceptor (PNP) that led to end the reduction reaction in $28 \mathrm{~min}$. The UV-vis spectroscopy technique was used for monitoring the catalyzed reduction reaction of PNP. Under alkaline conditions, PNP is characterized with an absorption peak at $400 \mathrm{~nm}$ and the reduction to PAP occurs with changing the PNP intense yellow color into colorless PAP solution with growing of another peak at $310 \mathrm{~nm}$ that is characteristic to PAP as shown in Fig. 6. After $48 \mathrm{~min}$, the reduction reaction finished using $1 \mathrm{mg}$ of the MTPS nanocatalyst. Pseudo first order assumption was applied to calculate the kinetic rate of this reduction reaction because of the high concentration of $\mathrm{NaBH}_{4}$ relative to PNP. The linear relation between $-\ln A_{t} / A_{\mathrm{o}} v s$. time is shown in Fig. $\mathrm{S} 3 \mathrm{~A} \dagger$ and the rate constant $(k)$ of the reduction reaction was calculated to be $0.1168 \mathrm{~min}^{-1}$. This rate constant is high as compared to previous articles, as shown in Table 1. Fig. S3B $\dagger$ shows clearly the decrease of the characteristic absorbance of PNP with time.

To further investigate the influence of catalyst amount, $2 \mathrm{mg}$ and $3 \mathrm{mg}$ of the synthesized MTPS nanocatalyst was used. Only $12 \mathrm{~min}$ and $6 \mathrm{~min}$ are needed to complete PNP reduction reaction using $2 \mathrm{mg}$ and $3 \mathrm{mg}$ of MTPS nanocatalyst as shown in Fig. S4A and $\mathrm{B}, \uparrow$ respectively.

Another important property for catalyst is its stability over many catalytic cycles. Upon repeating the catalysis test after the magnetic separation of the nanocatalyst as shown in Fig. 7(A and B), $85 \%$ of catalysis efficiency was achieved after five times of magnetic separation and catalyst reuse was obtained. The recovery and the separation strategy of the synthesized MTPS nanocatalyst is expressed by Fig. 8 .

Separately for comparing purpose, the catalytic activities of $\mathrm{Fe}_{3} \mathrm{O}_{4}$ NPs, $\mathrm{Fe}_{3} \mathrm{O}_{4} @ \mathrm{TiO}_{2}$ nanospheres, $\mathrm{Fe}_{3} \mathrm{O}_{4} @ \mathrm{TiO}_{2} / \mathrm{PPY}$, and MTPS nanocomposites were examined using the same conditions of MTPS nanocatalyst (Fig. 9). The obtained results show that the PNP reduction by $\mathrm{Fe}_{3} \mathrm{O}_{4} @ \mathrm{TiO}_{2}$ a relatively long time, due to the low response to the visible light. After the

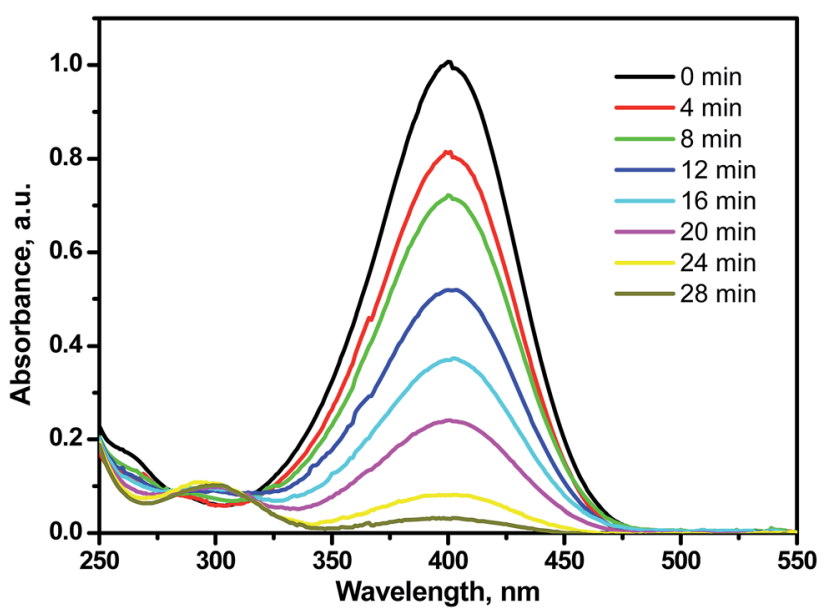

Fig. 6 UV-vis spectra for the reduction of PNP using $1 \mathrm{mg}$ MTPS nanocatalyst. 
Table 1 Rate constant of some catalysts compared with MTPS magnetic nanocomposite

\begin{tabular}{|c|c|c|c|}
\hline Substrate & Dose & $k\left(\times 10^{-3} \mathrm{~s}^{-1}\right)$ & Ref. \\
\hline$p$ (AMPS)-Co composite ${ }^{a}$ & $50 \mathrm{mg}$ & 2.0 & 48 \\
\hline $\mathrm{Ag}$-PPY-graphene oxide & $1.2 \mathrm{mg}$ & 0.288 & 49 \\
\hline (Ag NPs) on natural egg shell membrane (ESM) & $15 \mathrm{mg}$ & 2.90 & 51 \\
\hline $\mathrm{Fe}_{3} \mathrm{O}_{4} @ \mathrm{SiO}_{2}-\mathrm{Ag}$ & $1 \mathrm{~g}$ & 7.67 & 52 \\
\hline$p$ (AMPS) $-\mathrm{Cu}^{b}$ & 10 & 1.72 & 53 \\
\hline $\mathrm{Ag} / \mathrm{HHP}^{d}$ & $1 \mathrm{mg}$ & 0.50 & 56 \\
\hline $\mathrm{Ag}_{10} @ \mathrm{SBA}-15^{e}$ & $0.9 \mathrm{mg}$ & 0.127 & 57 \\
\hline $\mathrm{Fe}_{3} \mathrm{O}_{4} @ \mathrm{C} / \mathrm{Pd}$ & $2 \mathrm{mg}$ & 3.25 & 58 \\
\hline $\mathrm{Ag}^{0} @ \mathrm{CMP}^{f}$ & $7.4 \mathrm{mg}$ & 1.36 & 59 \\
\hline Ni NPs & $90 \mathrm{mg}$ & 2.7 & 60 \\
\hline $\mathrm{NAP}-\mathrm{Mg}-\mathrm{Au}(0)^{g}$ & $15 \mathrm{mg}$ & 7.60 & 61 \\
\hline
\end{tabular}

incorporation of PPY, the $\mathrm{Fe}_{3} \mathrm{O}_{4} @ \mathrm{TiO}_{2} / \mathrm{PPY}$ nanocomposite responds easily toward the visible light and the percentage of PNP removal is about $92 \%$ PNP in a relatively short time. However, in the existence of noble metal (silver) NPs, the catalytic properties of the MTPS nanocomposite was enhanced, and $100 \%$ PNP removed in approximately 28 minutes, which confirmed that MTPS nanocomposite has higher absorption in the visible light region than the other nanocatalyst. These results can be attributed to the surface plasmon resonance of silver in the visible light region, and to the synergistic effect among all components that enhanced the photocatalytic activity.

The photocatalytic activity of as-synthesized MTPS nanocomposite was studied toward $\mathrm{MB}$ degradation as a model reaction. The adsorption of $\mathrm{MB}$ on the surface of the synthesized MTPS photocatalyst was first investigated by following the degradation of $\mathrm{MB}$ after in dark to prevent the photodegradation process. Under the dark condition and after the addition of MTPS nanocomposite to MB dye solution, the absorbance of the MB solution was followed at different intervals of time. As shown as Fig. S5, $\dagger$ poor MB degradation in the dark condition was found as only $30 \%$ of $\mathrm{MB}$ was removed during $1.5 \mathrm{~h}$, which can be attributed to the adsorption of $\mathrm{MB}$ on the surface of MTPS nanocomposite.

Bare $\mathrm{TiO}_{2}$ can absorb only UV light while PPY can absorb both UV and visible lights and hence the absorption is expected to be shifted to the visible region upon the modification of $\mathrm{TiO}_{2}$ with PPY. ${ }^{18}$ Therefore, the conjunction between $\mathrm{TiO}_{2}$ and PPY, in the MPTS nanocomposite should exposes the advantages of both of them and thus, PPY can extend the $\mathrm{TiO}_{2}$ photoresponse to the visible region (400-800 $\mathrm{nm}$ ). Under the normal day light, $40 \mathrm{mg}$ of MPTS nanophotocatalyst was added to $100 \mathrm{~mL} \mathrm{MB}$ solution $\left(4 \mathrm{mg} \mathrm{L}^{-1}\right)$ for evaluation of the photocatalytic performance. As shown in Fig. 10, the MB dye degraded at significant rate in the presence of MTPS nanocomposite as a photocatalyst, temporal absorbance changes in the $\mathrm{MB}$ spectra was observed in the first 10 minutes with more than $60 \%$ of $\mathrm{MB}$ removal, which indicates a rapid degradation rate of MB dye. Furthermore, around $90 \%$ of MB was degraded in approximately less than one hour.

The robust photocatalytic activity exhibited by the MPTS nanophotocatalyst could be attributed to the MB photosensitization and the punchy synergistic effect of $\mathrm{TiO}_{2}$ and PPY. The coupling of PPY with $\mathrm{TiO}_{2}$ was found to induce an interesting charge transfer by which the attached PPY particles on $\mathrm{TiO}_{2}$ surface lead to driving the photogenerated electrons to depart away from the $\mathrm{TiO}_{2}$ and transferring the charge between the coupled semiconductors. ${ }^{62}$ In addition, the photocatalytic reaction was enhanced by increasing the reactive sites in the presence of PPY NPs. ${ }^{63}$ In addition to its role as an electron donor after the visible light irradiation, PPY worked as a hole acceptor. ${ }^{64}$ These interesting characteristics of PPY with $\mathrm{TiO}_{2}$ make them an ideal material to reach enhanced charge separation efficiency in the field of photocatalysis. In addition to the above inimitability characteristics, silver NPs possessed enhanced photocatalytic activity due to its surface plasmon resonance and hence, it can strongly absorb visible light, which lead to maximizing its ability to activate the reactive sites by working as electron traps. ${ }^{65}$

The photodegradation of $\mathrm{MB}$ was followed by tracking the concentration changes $\left(C / C_{0}\right)$ as a function of the visible light illumination time. The dye photodegradation efficiencies can be calculated from the equation:

$$
\text { Efficiency }(\%)=\left(C_{0}-C\right) / C_{0} \times 100 \%
$$



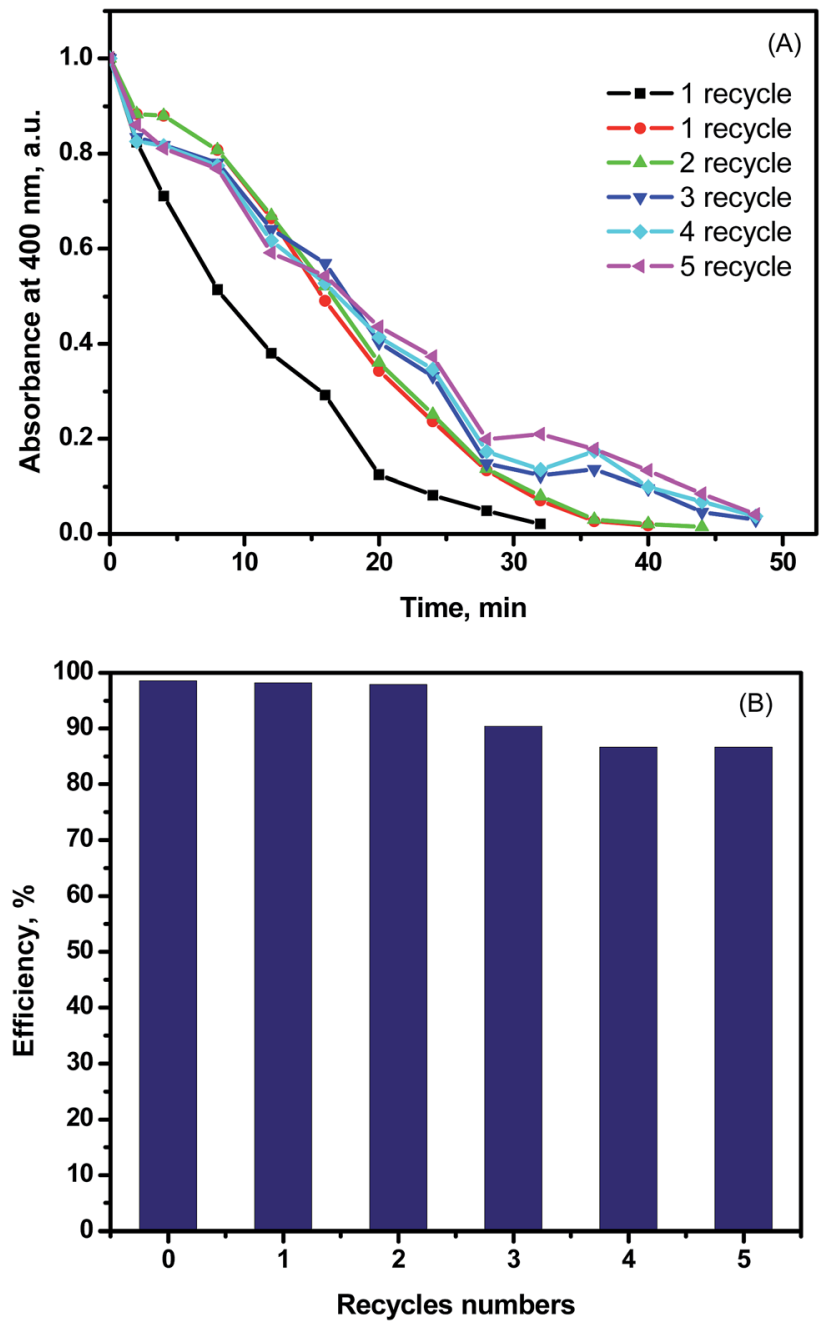

Fig. 7 Reusability of $1 \mathrm{mg}$ of MTPS nanocatalyst for the PNP reduction.

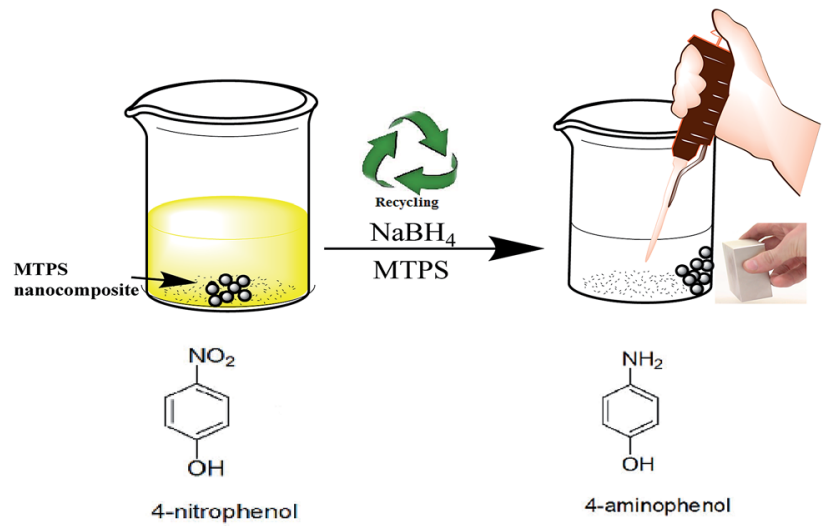

Fig. 8 The separation technique of the heterogeneous MTPS nanocatalyst.

where, $C_{0}$ is the initial MB dye concentration, $C$ is the MB dye concentration after photoirradiation.

As shown in Fig. S6, $\uparrow$ the photodegradation process was found to follow the pseudo first-order kinetics by linear

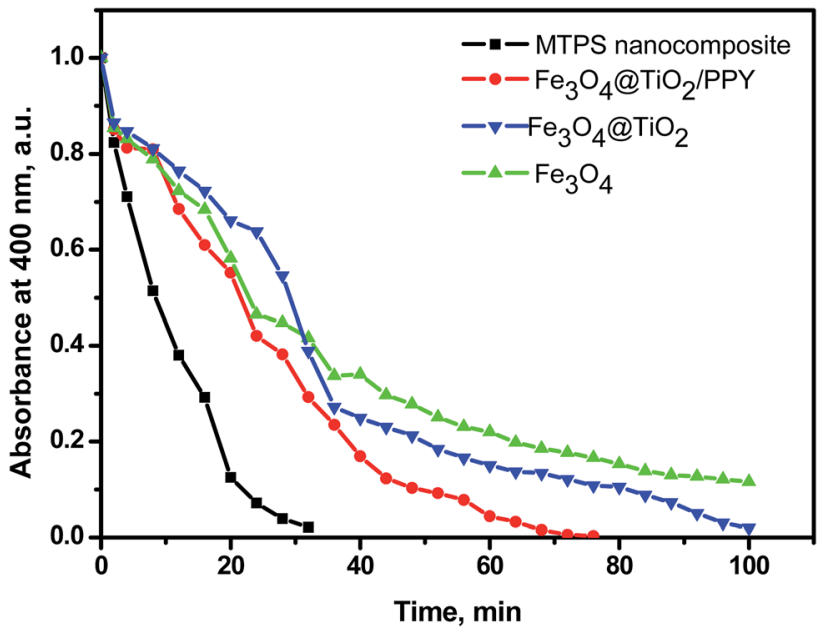

Fig. 9 Absorbance change during PNP reduction using different precursor materials as nanocatalysts.

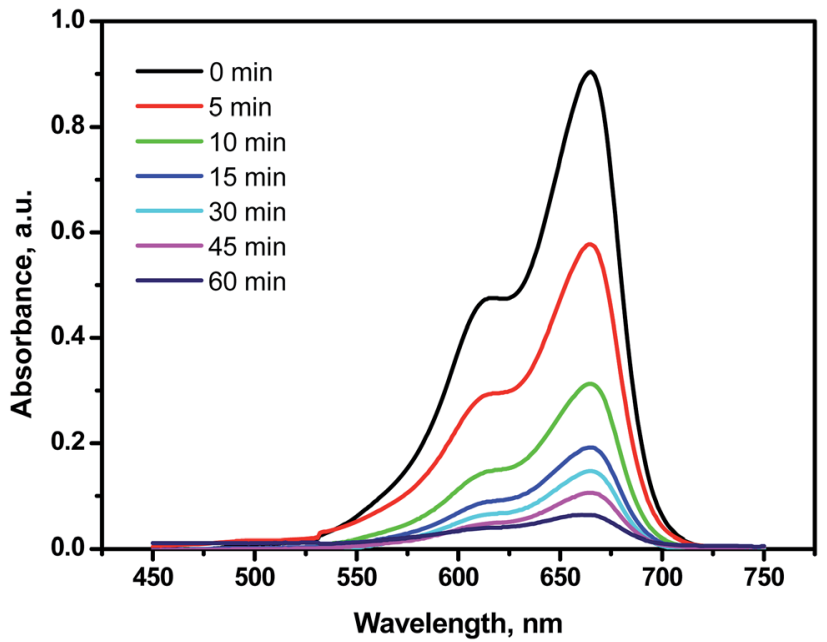

Fig. 10 Time-resolved photocatalytic spectra of $M B$ dye $\left(4 \mathrm{mg} \mathrm{L}^{-1}\right)$ upon the treatment with $0.04 \mathrm{~g}$ of MTPS nanophotocatalyst under the normal day light.

transform ${ }^{66}$ of the equation, $\ln \left(q_{\mathrm{o}} / q_{t}\right)=k t$, where $q_{\mathrm{o}}$ is the adsorption equilibrium concentration of $\mathrm{MB}, q_{t}$ is the concentration of $\mathrm{MB}$ at time $t$, and $k$ is the rate constant, which was estimated to be $6.38 \times 10^{-2} \mathrm{~min}^{-1}$ with a high correlation coefficient $\left(R^{2}=0.98\right)$ using only $40 \mathrm{mg}$ the synthesized MTPS nanophotocatalyst after irradiation for $1 \mathrm{~h}$.

The photocatalytic process includes a primary reaction step in which MB dye was firstly adsorbed onto the surface of MTPS nanophotocatalyst at PPY layer, while a secondary step is initiated by illumination the MTPS nanophotocatalyst with visible light producing electrons and holes, which generate reactive oxygen molecules. $\mathrm{TiO}_{2}$ consist of valence band (VB) and conduction band (CB) with band gap energy of $3.2 \mathrm{eV}$. PPY is an optimal conjugated polymer without reached $\pi$-conjugated electron systems and its band gap is $1.30-2.32 \mathrm{eV}^{67}$ so it is considered as a good hole transporter and an efficient electron donor under visible-light 


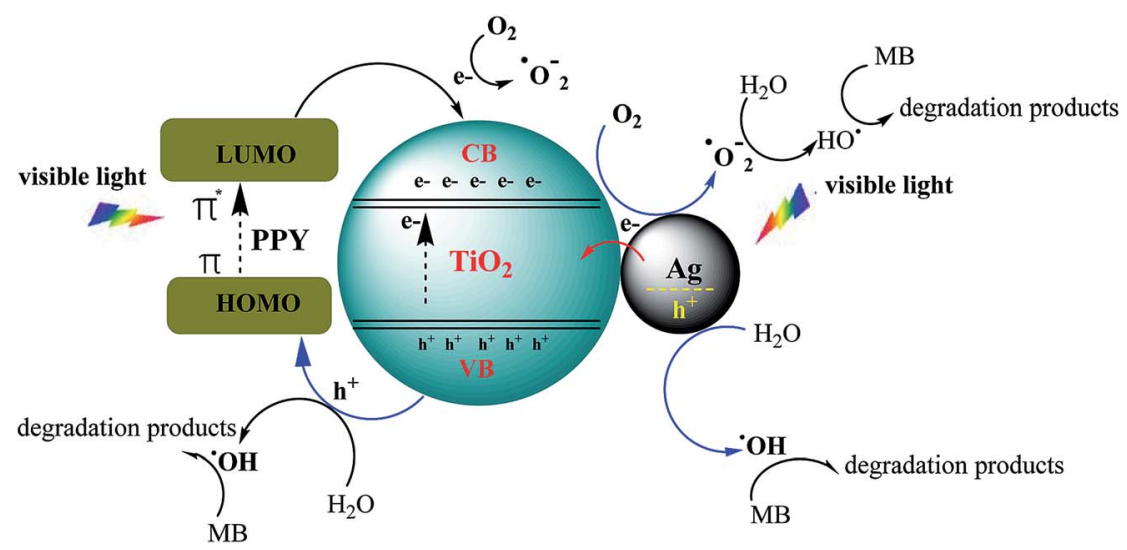

Scheme 2 Mechanism of MTPS nanocomposite to enhance the photocatalytic activity under visible light.

The proposed degradation mechanism of MB:

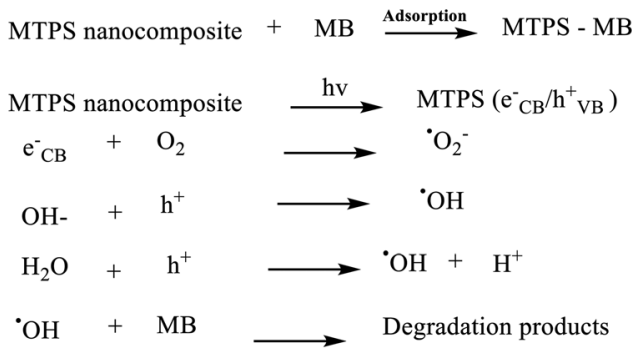

Scheme 3 A proposed mechanism for MB dye degradation using MTPS nanocomposite as a nanophotocatalyst under the normal day visible light.

excitation. On the other hand, $\mathrm{Ag}$ acts as an electron trapper and can prevent the electron-hole pairs from recombination process and subsequently permitting a grander proportion of hydroxyl radicals. When the MTPS nanophotocatalyst is illuminated with the visible light, PPY absorbs light to induce $\pi \rightarrow \pi^{*}$ transition, the excited electrons are transported to the $\pi^{*}$ orbital, which easily injected into the $\mathrm{CB}$ of $\mathrm{TiO}_{2}$. Afterward, the electrons are transferred to the surface, then react with the adsorbed $\mathrm{H}_{2} \mathrm{O}$ and $\mathrm{O}_{2}$ to yield hydroxyl and superoxide radicals. ${ }^{66}$ In the meantime, the electron-hole pairs direct recombination would be potently inhibited, because excited electrons are injected into CB of $\mathrm{TiO}_{2}$, which provide holes on PPY. ${ }^{17}$ These electrons react with $\mathrm{O}_{2}$ generating $\cdot \mathrm{O}_{2}$ and holes that can react with $\mathrm{OH}^{-}$or $\mathrm{H}_{2} \mathrm{O}$ to produce $\cdot \mathrm{OH}$ that in turn reacts with $\mathrm{MB}$ dye in a degradation procedures as shown in Scheme $2 .^{68}$ A suggested photodegradation mechanism of MB dye by using MTPS nanocomposite as a nanophotocatalyst is shown in Scheme $3 .^{5}$

MTPS nanocomposite was found to exhibit an excellent photocatalytic degradation behavior toward MB dye, and the apparent first-order rate constant was higher than many other reported

Table 2 Photoactivity of some photocatalysts compared with MTPS nanocomposite

\begin{tabular}{|c|c|c|c|c|c|}
\hline $\mathrm{TiO}_{2} / \mathrm{SiO}_{2} / \mathrm{Ni}-\mathrm{Cu}-\mathrm{Zn}$ & $400 \mathrm{mg}$ & 360 & 3.18 & Visible light & 69 \\
\hline $\mathrm{Fe}_{2} \mathrm{O}_{3} / \mathrm{PPY} / \mathrm{Ag}$ & $8 \mathrm{mg}$ & 120 & 8 & UV light & 70 \\
\hline $\mathrm{Fe}_{3} \mathrm{O}_{4} @ \mathrm{Ag} @ \mathrm{PPY}$ & $2 \mathrm{mg}$ & 120 & 1 & UV light & 71 \\
\hline $\mathrm{Fe}_{3} \mathrm{O}_{4} @ \mathrm{PANI} / \mathrm{TiO}_{2}$ & $30 \mathrm{mg}$ & 140 & 19.7 & Visible light & 72 \\
\hline $\mathrm{PPY}-\mathrm{PANI} / \mathrm{TiO}_{2}$ & $150 \mathrm{mg}$ & 120 & 8 & Visible light & 74 \\
\hline${ }^{a} \mathrm{MIP}-\mathrm{PPY} / \mathrm{TiO}_{2}$ & $20 \mathrm{mg}$ & 120 & 15.04 & Visible light & 5 \\
\hline $\mathrm{Ag} / \mathrm{Ag}_{2} \mathrm{O} / \mathrm{TiO}_{2} @ \mathrm{PPY}$ & $100 \mathrm{mg}$ & 100 & 3 & UV light & 54 \\
\hline $\mathrm{TiO}_{2}-\mathrm{WO}_{3}$ & $30 \mathrm{mg}$ & 240 & 27 & Visible light & 75 \\
\hline Double-shelled $\mathrm{TiO}_{2} @ \mathrm{WO}_{3} / \mathrm{Au}$ & $30 \mathrm{mg}$ & 240 & 52 & Visible light & 75 \\
\hline $\mathrm{TiO}_{2}-\mathrm{Al}$ & $2 \mathrm{~g} \mathrm{~L}^{-1}$ & 180 & 14.2 & Visible light & 76 \\
\hline MTPS nanocomposite & $40 \mathrm{mg}$ & 60 & 63.8 & Visible light & This work \\
\hline
\end{tabular}

\footnotetext{
${ }^{a}$ Molecular imprinting technique. ${ }^{b}$ Reduced graphene oxide/anatase $\mathrm{TiO}_{2}$ composite.
} 
substrates, with an optimal dose and irradiation time as shown in Table 2. After comparing the catalyst dose, irradiation time, the used light, and the rate constant in Table 2, it can be found clearly that our synthesized performs the best.

\section{Conclusion}

In summary, a simple, low coast, and efficient method was presented to synthesize bifunctional MTPS nanocomposite with an enhanced catalytic and photocatalytic activity accompanied with good recyclability and magnetic performance. The structure was fabricated by depositing a shell of $\mathrm{TiO}_{2}$ onto the surface of $\mathrm{Fe}_{3} \mathrm{O}_{4}$ magnetic core followed by coating with a layer of PPY and its decoration with silver NPs. The morphology investigation showed the inclusion of the main elements in the synthesized MTPS nanocomposite. A good catalytic conversion of PNP to PAP employing MTPS as a nanocatalyst were achieved with a rate constant of $11.682 \times 10^{-2} \mathrm{~min}^{-1}$. The catalytic activities of $\mathrm{Fe}_{3} \mathrm{O}_{4} \mathrm{NPs}, \mathrm{Fe}_{3} \mathrm{O}_{4} @ \mathrm{TiO}_{2}, \mathrm{Fe}_{3} \mathrm{O}_{4} @ \mathrm{TiO}_{2} / \mathrm{PPY}$, and MTPS nanocomposites catalytic activities were compared where, $\mathrm{Fe}_{3} \mathrm{O}_{4}$ and $\mathrm{Fe}_{3} \mathrm{O}_{4} @ \mathrm{TiO}_{2}$ nanocatalysts possessed the lowest rate toward PNP reduction while the coexistence of PPY and Ag NPs led to the maximum PNP reduction rate and 100\% PNP removed in approximately 28 minutes using MTPS nanocatalyst due to the surface plasmon resonance in visible light region of silver and the synergetic effect of PPY and silver for narrowing of $\mathrm{TiO}_{2}$ band gap. Moreover, the as-synthesized MTPS nanocomposite was found to possess a high photocatalytic activity toward MB degradation with a rate constant of $63.8 \times 10^{-3} \mathrm{~min}^{-1}$. The dual activity of the synthesized nanocatalyst is the novel point in this work due to its unique structure and properties that paves the way toward a superior catalytic and photocatalytic behavior under visible light. A small loss of MTPS nanocomposite was found by the recycling test, so that the efficiency was more than $85 \%$ after five cycles.

\section{Conflicts of interest}

The authors declare that they have no conflict of interest.

\section{Acknowledgements}

The authors thank Faculty of Science, Tanta University and the Egyptian Academy of Scientific Research and Technology for their financial support.

\section{References}

1 D. Astruc, F. Lu and J. R. Aranzaes, Angew. Chem., Int. Ed., 2005, 44, 7852-7872.

2 J. Li, X. a. Dong, G. Zhang, W. Cui, W. Cen, Z. Wu, S. Lee and F. Dong, J. Mater. Chem. A, 2019, 7, 3366-3374.

3 X. Li, W. Zhang, W. Cui, J. Li, Y. Sun, G. Jiang, H. Huang, Y. Zhang and F. Dong, Chem. Eng. J., 2019, 370, 1366-1375.

4 Y. Du, H. Chen, R. Chen and N. Xu, Appl. Catal., A, 2004, 277, 259-264.
5 F. Deng, Y. Li, X. Luo, L. Yang and X. Tu, Colloids Surf., A, 2012, 395, 183-189.

6 L. Zhang, X. Liu, Y. Wang and S. Xing, J. Alloys Compd., 2017, 709, 431-437.

7 M. M. Ayad, W. A. Amer, S. Zaghlol, N. Maráková and J. Stejskal, Cellulose, 2018, 25, 7393-7407.

8 X. Zhang, W.-x. Zhi, B. Yan and X.-x. Xu, Powder Technol., 2012, 221, 177-182.

9 S. Bagheri, A. TermehYousefi and T.-O. Do, Catal. Sci. Technol., 2017, 7, 4548-4569.

10 S. Sakthivel, S.-U. Geissen, D. Bahnemann, V. Murugesan and A. Vogelpohl, J. Photochem. Photobiol., A, 2002, 148, 283-293.

11 F. S. Sangsefidi, M. Salavati-Niasari, H. Khojasteh and M. Shabani-Nooshabadi, Int. J. Hydrogen Energy, 2017, 42, 14608-14620.

12 D. Toloman, O. Pana, M. Stefan, A. Popa, C. Leostean, S. Macavei, D. Silipas, I. Perhaita, M. D. Lazar and L. Barbu-Tudoran, J. Colloid Interface Sci., 2019, 542, 296307.

13 I. Ali, M. Suhail, Z. A. Alothman and A. Alwarthan, RSC Adv., 2018, 8, 30125-30147.

14 L. Han, B. Su, G. Liu, Z. Ma and X. An, Mol. Catal., 2018, 456, 96-101.

15 Q. Luo, X. Li, D. Wang, Y. Wang and J. An, J. Mater. Sci., 2011, 46, 1646-1654.

16 R. J Ramirez, C. AP Arellano, J. C Varia and S. S Martinez, Curr. Org. Chem., 2015, 19, 540-555.

17 D. Wang, Y. Wang, X. Li, Q. Luo, J. An and J. Yue, Catal. Commun., 2008, 9, 1162-1166.

18 Y. Yang, J. Wen, J. Wei, R. Xiong, J. Shi and C. Pan, ACS Appl. Mater. Interfaces, 2013, 5, 6201-6207.

19 B. Naik, V. Prasad and N. N. Ghosh, Powder Technol., 2010, 199, 197-201.

20 X. Lu, X. Bian, G. Nie, C. Zhang, C. Wang and Y. Wei, J. Mater. Chem., 2012, 22, 12723-12730.

21 E. Chen, H. Su, W. Zhang and T. Tan, Powder Technol., 2011, 212, 166-172.

22 D.-H. Kuo, W.-T. Hsu and Y.-Y. Yang, Appl. Catal., B, 2016, 184, 191-200.

23 P. Zhang, Y. Wang, Y. Zhou, H. Zhang, X. Wei, W. Sun, S. Meng and L. Han, Mol. Catal., 2019, 465, 24-32.

24 D. Maity and D. Agrawal, J. Magn. Magn. Mater., 2007, 308, 46-55.

25 H. Quanguo, Z. Lei, W. Wei, H. Rong and H. Jingke, Sens. Mater., 2010, 22, 285-295.

26 Y. Deng, Y. Cai, Z. Sun, J. Liu, C. Liu, J. Wei, W. Li, C. Liu, Y. Wang and D. Zhao, J. Am. Chem. Soc., 2010, 132, 84668473.

27 P. S. S. A. Kulkarni, K. P. Prakash and K. K. Kiran, Ceram. Int., 2014, 40, 1945-1949.

28 W. Hu, B. Liu, Q. Wang, Y. Liu, Y. Liu, P. Jing, S. Yu, L. Liu and J. Zhang, Chem. Commun., 2013, 49, 7596-7598.

29 J. Feng, N. Sun, D. Wu, H. Yang, H. Xu and W. Yan, J. Polym. Environ., 2017, 25, 781-791.

30 M. M. Ayad and E. Zaki, Appl. Surf. Sci., 2009, 256, 787-791. 
31 M. M. Ayad, W. A. Amer, M. G. Kotp, I. M. Minisy, A. F. Rehab, D. Kopecký and P. Fitl, RSC Adv., 2017, 7, 18553-18560.

32 Z. Zhu, X. Tang, C. Ma, M. Song, N. Gao, Y. Wang, P. Huo, Z. Lu and Y. Yan, Appl. Surf. Sci., 2016, 387, 366-374.

33 M. M. Ayad, W. A. Amer and M. G. Kotp, Mol. Catal., 2017, 439, 72-80.

34 A. Ehsani, M. Mahjani, M. Jafarian and A. Naeemy, Electrochim. Acta, 2012, 71, 128-133.

35 J.-G. Wang, B. Wei and F. Kang, RSC Adv., 2014, 4, 199-202.

36 Y. Zhao, C. Tao, G. Xiao, G. Wei, L. Li, C. Liu and H. Su, Nanoscale, 2016, 8, 5313-5326.

37 Y. Wang, B. Zou, T. Gao, X. Wu, S. Lou and S. Zhou, J. Mater. Chem., 2012, 22, 9034-9040.

38 L. Chen, L. Wu, F. Liu, X. Qi, Y. Ge and S. Shen, J. Mater. Chem. B, 2016, 4, 3660-3669.

39 S. Khashan, S. Dagher, N. Tit, A. Alazzam and I. Obaidat, Surf. Coat. Technol., 2017, 322, 92-98.

40 M. M. Ayad, J. Mater. Sci., 2009, 44, 6392-6397.

41 K. H. Kate, S. R. Damkale, P. Khanna and G. Jain, J. Nanosci. Nanotechnol., 2011, 11, 7863-7869.

42 P. Dallas, D. Niarchos, D. Vrbanic, N. Boukos, S. Pejovnik, C. Trapalis and D. Petridis, Polymer, 2007, 48, 2007-2013.

43 B. S. Singu and K. R. Yoon, Electrochim. Acta, 2018, 268, 304315.

44 X. Yang and Y. Lu, Mater. Lett., 2005, 59, 2484-2487.

45 S. Ye, L. Fang and Y. Lu, Phys. Chem. Chem. Phys., 2009, 11, 2480-2484.

46 W. Wu, C. Jiang and V. A. Roy, Nanoscale, 2015, 7, 38-58.

47 J. O. Marques Neto, C. R. Bellato, C. H. de Souza, R. C. d. Silva and P. A. Rocha, J. Braz. Chem. Soc., 2017, 28, 2301-2312.

48 N. Sahiner, H. Ozay, O. Ozay and N. Aktas, Appl. Catal., B, 2010, 101, 137-143.

49 V. Balakumar and P. Prakash, J. Catal., 2016, 344, 795-805.

50 Y. Snoussi, S. Bastide, M. Abderrabba and M. M. Chehimi, Ultrason. Sonochem., 2018, 41, 551-561.

51 M. Liang, R. Su, R. Huang, W. Qi, Y. Yu, L. Wang and Z. He, ACS Appl. Mater. Interfaces, 2014, 6, 4638-4649.

52 Y. Chi, Q. Yuan, Y. Li, J. Tu, L. Zhao, N. Li and X. Li, J. Colloid Interface Sci., 2012, 383, 96-102.

53 N. Sahiner and O. Ozay, Curr. Nanosci., 2012, 8, 367-374.

54 R. Kumar, R. M. El-Shishtawy and M. A. Barakat, Catalysts, 2016, 6, 76.

55 S. Tang, S. Vongehr and X. Meng, J. Phys. Chem. C, 2010, 114, 977-982.

56 M. Gopiraman, S. Saravanamoorthy and I.-M. Chung, Res. Chem. Intermed., 2017, 43, 5601-5614.

57 S. BhanudasNaik, V. S. Prasad and N. N. Ghosh, Catal. Commun., 2011, 12, 1104-1108.
58 T. Yao, Q. Zuo, H. Wang, J. Wu, B. Xin, F. Cui and T. Cui, J. Colloid Interface Sci., 2015, 450, 366-373.

59 H.-L. Cao, H.-B. Huang, Z. Chen, B. Karadeniz, J. Lü and R. Cao, ACS Appl. Mater. Interfaces, 2017, 9, 5231-5236.

60 A. Wang, H. Yin, H. Lu, J. Xue, M. Ren and T. Jiang, Catal. Commun., 2009, 10, 2060-2064.

61 K. Layek, M. L. Kantam, M. Shirai, D. Nishio-Hamane, T. Sasaki and H. Maheswaran, Green Chem., 2012, 14, 3164-3174.

62 S. Sarmah and A. Kumar, Indian J. Phys., 2011, 85, 713.

63 X. Huang, G. Wang, M. Yang, W. Guo and H. Gao, Mater. Lett., 2011, 65, 2887-2890.

64 Y. Shirota and H. Kageyama, Chem. Rev., 2007, 107, 9531010.

65 P. Wang, B. Huang, Y. Dai and M.-H. Whangbo, Phys. Chem. Chem. Phys., 2012, 14, 9813-9825.

66 H. Zhang, R. Zong, J. Zhao and Y. Zhu, Environ. Sci. Technol., 2008, 42, 3803-3807.

67 M. M. Abdi, H. E. Mahmud, L. C. Abdullah, A. Kassim, M. Z. A. Rahman and J. L. Y. Chyi, Chin. J. Polym. Sci., 2012, 30, 93-100.

68 S. A. Ansari, M. M. Khan, M. O. Ansari, J. Lee and M. H. Cho, New J. Chem., 2014, 38, 2462-2469.

69 C. C. Chen, Y. P. Fu and S. H. Hu, J. Am. Ceram. Soc., 2015, 98, 2803-2811.

70 Y. Cheng, F. Gao, L. An, J. Lan, X. Li and G. Wang, Res. Chem. Intermed., 2015, 41, 1741-1755.

71 Y. Cheng, F. Gao, L. An, X. Li and G. Wang, Adv. Powder Technol., 2014, 25, 1600-1607.

72 W. Li, Y. Tian, C. Zhao, Q. Zhang and W. Geng, Chem. Eng. J., 2016, 303, 282-291.

73 N. Guo, Y. Liang, S. Lan, L. Liu, J. Zhang, G. Ji and S. Gan, J. Phys. Chem. C, 2014, 118, 18343-18355.

74 F. Deng, L. Min, X. Luo, S. Wu and S. Luo, Nanoscale, 2013, 5, 8703-8710.

75 J. Cai, X. Wu, S. Li and F. Zheng, ACS Sustainable Chem. Eng., 2016, 4, 1581-1590.

76 N. Areerachakul, S. Sakulkhaemaruethai, M. Johir, J. Kandasamy and S. Vigneswaran, J. Water Process Eng., 2019, 27, 177-184.

77 J.-A. Park, B. Yang, J. Lee, I. G. Kim, J.-H. Kim, J.-W. Choi, H.-D. Park, I. W. Nah and S.-H. Lee, Chemosphere, 2018, 191, 738-746.

78 N. Wang, X. Li, Y. Yang, T. Guo, X. Zhuang, S. Ji, T. Zhang, Y. Shang and Z. Zhou, Sep. Sci. Technol., 2019, 211, 673-683.

79 X. Wang, Y. Xiang, B. Zhou, Y. Zhang, J. Wu, R. Hu, L. Liu, J. Song and J. Qu, J. Colloid Interface Sci., 2019, 534, 1-11.

80 R. Fiorenza, M. Bellardita, S. Scirè and L. Palmisano, Mol. Catal., 2018, 455, 108-120. 